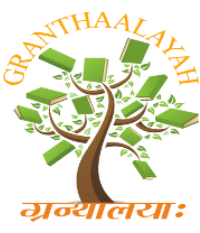

INTERNATIONAL JOURNAL OF RESEARCH GRANTHAALAYAH A knowledge Repository

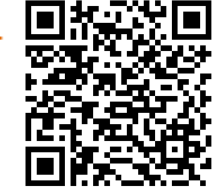

\title{
INTERNATIONAL ENVIRONMENTAL LAW AND CONSERVATION SCIENCE
}

\author{
Deepali Amb(prasad) ${ }^{1}$, Sanjay Prasad ${ }^{2}$ \\ ${ }^{1}$ S. V. Govt. P. G. College Neemuch (M.P.) \\ ${ }^{2}$ Govt. College Sanwer, Indore (M.P.)
}

\begin{abstract}
This paper work on international law the body of international law regulating human interaction with the natural world, little of the governance of natural resources, for example, is 'environmental'. Subsisting at the periphery, environmental law focuses on conserving particular species and 'ecosystems', and curbing certain kinds of pollution. Its principles are vague, peppering the margins of rulings within other judicial. The existing methods are slow, cumbersome, expensive, uncoordinated and uncertain. Something better must be found if the environmental challenges the world faces are to be dealt with successfully. Unless we devise a better way to make international law for the environment, future progress is likely to be piecemeal, fitful, unsystematic and even random. The justification for taking bold steps now rests on analysis of three factors: the formidable nature of the environmental issues that must be dealt with; the condition of international organization relating to the environment, particularly the United Nations system; and the methods currently used to make international environmental law. In this paper, we suggest that international environmental laws are due to two competing heritages. The "natural world as sacred, inviolable, and redemptive.
\end{abstract}

Keywords:

International Law, Environmental, Conservation, Ecosystem \& United Nations.

\section{INTRODUCTION}

\section{INTERNATIONAL ENVIRONMENTAL LAW}

Imagine a world in which environmental change people's health, physical security, material needs and social cohesion. This is a world beset by increasingly intense and frequent storms, and by rising sea levels. Some people experience, extensive flooding, while others endure intense droughts. Species extinction occurs at rates never before witnessed. Safe water is increasingly limited, hindering economic activity. Land degradation endangers the lives of millions of people. This is the world today. International environmental law is progressively a tool for global public health protection. The major sources of international environmental law include treaties, international custom, general principles of law, and subsidiary sources such as decisions of courts and tribunals and the writings of jurists. However, treaties are the major source of international law for the environment. A number of principles emerged from the 1992 U.N. Conference on Environment and Development ("UNCED"), other declarations, and the ensuing conventions, and have supported the development of international environmental law. 


\title{
ENVIRONMENTAL LAWS IN GENERAL
}

Environmental laws are the standards that Governments establish to manage natural resources and environmental quality. The broad categories of "natural resources" and "environmental quality" include such areas as air and water pollution, forests and wildlife, hazardous waste, agricultural practices, wetlands, and land use planning. The body of environmental law includes not only the text of these laws, but also the regulations that implement and the judicial decisions that interpret this legislation. In general, the standards set forth in environmental laws can apply to either private parties or the Government.

\begin{abstract}
AIMS
The aims and subject matter of international environmental agreements has changed dramatically since such agreements were first introduced. Early agreements focused on issues relating to Boundary Rivers, fishing rights and the protection of flora and fauna. Today, agreements cover a much wider range of issues, including conservation of habitats and biodiversity, controlling pollution and protection of resources located within countries that are of concern to the international community.

Since the Rio Conference on Environment and Development in 1992 (the "Rio Conference"), we have also seen an increased awareness that environmental issues and economic issues are intrinsically linked; as a result, sustainable development and associated legislation/guidance has also been a key feature. The international community is aware that it is important not only to monitor and research, environmental risks, but also to reduce them. The aims of states have moved from international agreements that mainly address research, information exchange and monitoring to agreements that require reductions in pollutant emissions and changes in control technology.
\end{abstract}

\section{KEY FEATURES}

Covering all of the vast number of international legal instruments that deal with international environmental law is impossible within this guide. However, from the large body of agreements, it is possible to discern general principles which are frequently endorsed in practice:

1 States have sovereignty over their natural resources and the responsibility not to cause environmental damage, a principle originating from the Stockholm Declaration on the Human Environment 1972.

2 In the absence of scientific consensus that an action is harmful, the burden of proof that it is not harmful falls on the person taking the action (the Precautionary principle). This principle appears in a number of legal instruments including the Rio Declaration (Principle 15) and the Montreal Bio safety Protocol 2000.

3 The party responsible for producing pollution is responsible for paying for the damage done to the environment (the Rio Declaration 1992 states that the "polluter should, in principle, bear the cost of pollution" (Principle 16)).

4 Sustainable development - this concept can be found expressly and implicitly in many environmental treaties and can broadly be defined as "development that meets the needs of the present without compromising the ability of future generations to meet their own need." For example, the Stockholm Declaration on the Human Environment 1972, although not a binding legal instrument, recognises that most of the environmental problems in developing countries are caused by underdevelopment and poverty and as a result, development should be focused on in such states (Principles 8 and 9 of the Stockholm Declaration). 
Due to a lack of judicial authority and often conflicting interpretations under state practice, it is difficult to establish the precise international legal status of each general principle. As a result, the legal consequences in each case depend on the facts and circumstances of that particular case. The legal meaning and consequences of the above principles remain open. As there is no agreement as yet concerning their legal consequences, it is unlikely that they will be used, at least at the present time, to compel the international community to protect the environment. It remains for international tribunals such as the International Court of Justice to effectively codify these principles to give rise to legal obligations and legal remedies.

\section{THIS IS THE WORLD TODAY}

Climate change is one of the most significant of the many global environmental challenges. While our understanding of the causes and impacts of climate change was slow to emerge, it is no understatement to say that climate change is the greatest threat facing humanity and all life on Earth today. While all regions of the world will be impacted by climate change, it is the poor and especially the developing countries that are the most vulnerable. Especially the heavily populated mega delta regions in South, East and Southeast Asia, are projected to be at increased risk of flooding for small island communities, sea level rise is expected to exacerbate inundation, storm surge, erosion and other coastal hazards and threaten vital infrastructure, settlements and facilities upon which island communities.

\section{Key figures from this assessment worth highlighting include}

- There were 869 recorded extinctions, with 804 species listed as extinct and 65 listed as extinct In the wild.

- The number of extinction increases to 1159 if the 290 critically endangered species tagged as "Possibly extinct" are included.

- 16928 species are threatened with extinction (3246 are critically endangered, 4770 are Endangered and 8912 are vulnerable).

- 3796 species are listed as near threatened; and 5570 species have insufficient information to Determine their threat status and are listed as data deficient.

Climate change and the alarming rates of biodiversity loss are but two examples of the many environmental problems humanity have faced over the past few decades. These challenges are in turn closely linked to development and human well-being. The global community has taken steps to seek to tackle many of these environmental challenges. These attempts have seen a veritable boom in the development of international environmental law. There are now more than 900 multilateral and over 1500 bilateral treaties and other international agreements dealing with environmental issues. These are in addition to the thousands of "soft law" instruments such as declarations and plans of action which have been the product of environmental diplomacy in recent decades. But despite the proliferation of international environmental agreements, environmental degradation has proceeded and new environmental challenges have continued to emerge. But given the experience, some might say the failure, of international environmental law to deal with existing environmental challenges before turning to consider new and emerging challenges. It is useful to consider the history of international environmental law and what lessons we may learn from that history. 


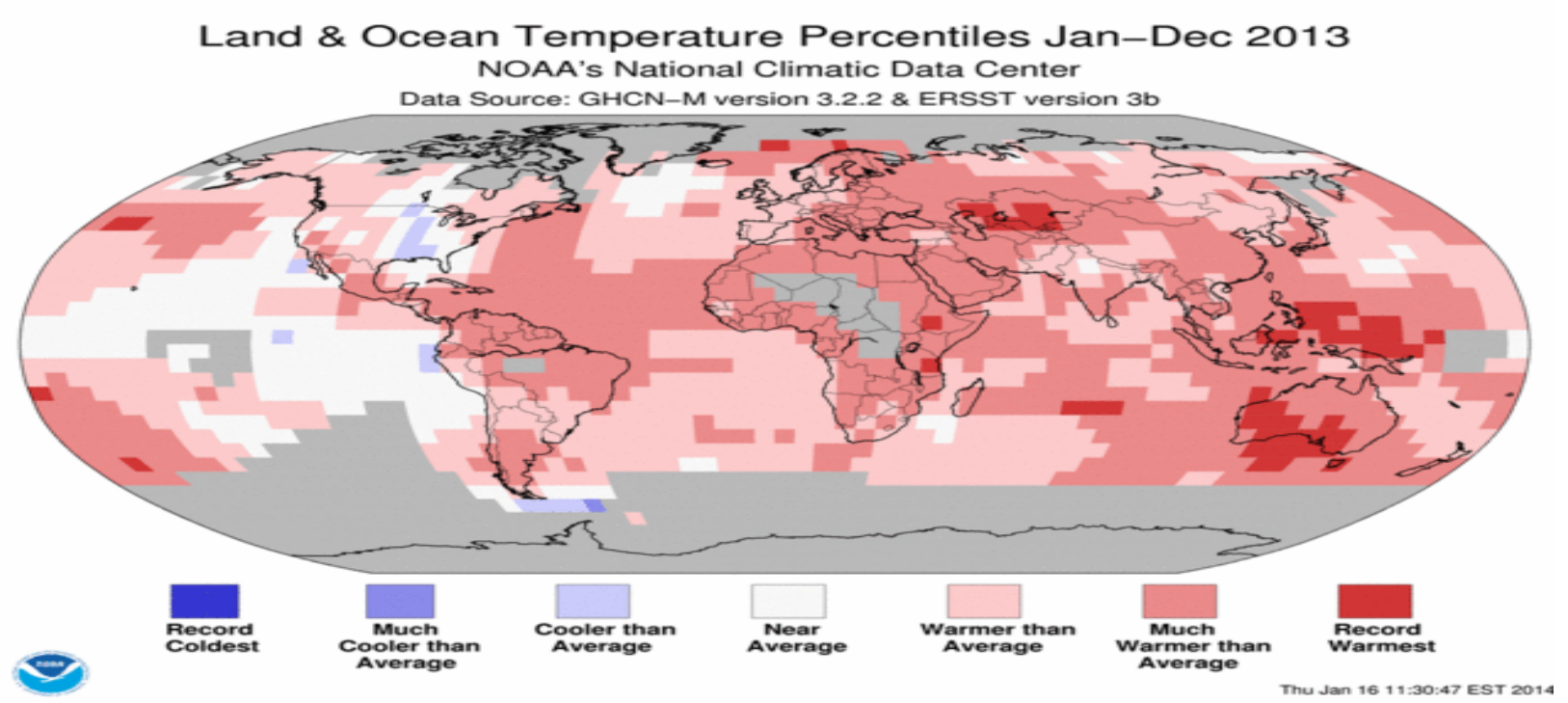

Climate change will not only affect humans and human communities. By 2020, significant loss of biodiversity is projected to occur in many of the world's ecologically rich sites such as the Great Barrier Reef in Australia. There is also "a risk of significant biodiversity loss through species extinction in many areas of tropical Latin America". While the loss of biodiversity is already occurring, and in part is caused by climate change, it is also the result of many other human impacts. Threats to biodiversity come from varied sources including habitat destruction such as deforestation and modification and destruction of ecosystems for industrial, agricultural And other activities, overexploitation of resources, pollution, introduced species, to mention but a few. The loss of biodiversity is occurring at an alarming rate. An update of the IUCN Red List published in 2008, the world's leading source of information on the status of biodiversity, makes for sober reading. This update presented an assessment of only 44838 of the several millions of species thought to exist on Earth.

\section{CONCLUSION}

International environmental law is a vast topic which is receiving increasing legal and political attention. The global environmental system ignores political boundaries, so it is important that countries with the potential to impact the international environment are within the conventional system in order to avoid defeating the purposes of the agreement. Currently, a number of states are not implementing legislation at a national level, and a number of developing states are growing increasingly concerned about the economic consequences and impact on their development. This means that enforcement of the legislation is a major issue.

Countries usually accept or avoid international environmental obligations because it is in their economic self-interest to do so. Nations rarely take actions that may harm their domestic economy or their international trade for altruistic reasons. They take these actions expecting some economic or political benefit sooner or later.

\section{REFERENCES}

1. Biodiversity (Convention on Biological Diversity. http://www.biodiv.org

2. Climate change (United Nations Framework Convention on Climate Change and the Kyoto Protocol on Global Warming. http://unfccc.int 
3. Cultural preservation (Convention Concerning the Protection of the World Cultural \& Natural Heritage, http://whc.unesco.org

4. Desertification (United Nations Convention to Combat Desertification http://www.unccd.int

5. Endangered species (Convention on International Trade in Endangered Species (CITES)) http://www.cites.org

6. Patricia Birnie, Alan Boyle, and Catherine Redgewell, International Law and the Environment, 3rd edition (Oxford UP, 2009)

7. Philippe Sands, "Unilateralism, Values and International Law", European Journal of International Law, vol. 11, no. 2 (2000),

8. Principles of International Environmental Law (Cambridge: Cambridge University Press, 2003),

9. Sustainable development (The Rio Declaration on Environment and Development. http://www.unep.org 